\title{
Correction to: Heavy metal-induced oxidative stress on seed germination and seedling development: a critical review
}

\author{
Mihiri Seneviratne Nishanta Rajakaruna - Muhammad Rizwan • \\ H. M. S. P. Madawala $\cdot$ Yong Sik Ok $\cdot$ Meththika Vithanage
}

Published online: 27 December 2017

(C) Springer Science+Business Media B.V., part of Springer Nature 2017

\section{Correction to: Environ Geochem Health https://doi.org/10.1007/s10653-017-0005-8}

Unfortunately, in the original publication of the article, Prof. Yong Sik Ok's affiliation was incorrectly published. The author's affiliation is as follows.
1. Kangwon National University, Chuncheon 24341, Republic of Korea

2. O-Jeong Eco-Resilience Institute (OJERI), Division of Environmental Science and Ecological Engineering, Korea University, Seoul, Republic of Korea
The original article can be found online at https://doi.org/10.1007/s10653-017-0005-8.

\section{Seneviratne}

Department of Botany, Faculty of Natural Sciences, Open

University of Sri Lanka, Nawala, Nugegoda, Sri Lanka

N. Rajakaruna

Unit for Environmental Sciences and Management,

North-West University, Potchefstroom, South Africa

\section{N. Rajakaruna}

Biological Sciences Department, California Polytechnic

State University, San Luis Obispo, CA 93407, USA

\section{Rizwan}

Department of Environmental Sciences and Engineering, Government College University, Allama Iqbal Road, Faisalabad 38000, Pakistan

H. M. S. P. Madawala

Department of Botany, University of Peradeniya,

Peradeniya, Sri Lanka
Y. S. Ok $(\bowtie)$

Korea Biochar Research Center \& School of Natural Resources and Environmental Science, Kangwon National University, Chuncheon 24341, Korea

e-mail: soilok@kangwon.ac.kr

Y. S. Ok

O-Jeong Eco-Resilience Institute (OJERI), Division of Environmental Science and Ecological Engineering, Korea University, Seoul, Republic of Korea e-mail: yongsikok@korea.ac.kr

M. Vithanage $(\bowtie)$

Environmental Chemodynamics Project, National Institute of Fundamental Studies, Kandy, Sri Lanka e-mail: meththikavithanage@gmail.com

M. Vithanage

Office of the Dean, Faculty of Applied Sciences, University of Sri Jayewardenepura, Nugegoda, Sri Lanka 